\title{
DEPOIMENTO
}

\section{UMA EXPERIÊNCIA NA ESCANDINÁVIA}

Norma Seltzer Goldstein'

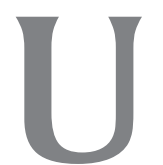

m convênio entre a Universidade de Oslo e a Universidade de São Paulo previa que, em abril de 1997, um curso de Português seria ministrado por docente brasileiro naquela instituição. Convidada para a tarefa, senti-me feliz em representar a área de Filologia e Língua Portuguesa da USP na Noruega. A viagem foi ampliada para os países vizinhos, pois as Universidades de Aårhus, na Dinamarca, e de Estocolmo, na Suécia, tinham interesse em palestras de pesquisadores de nossa universidade.

Fiquei vinte dias na instituição norueguesa e fiz rápida passagem pelas outras duas. A experiência foi muito rica, por isso creio que vale a pena relatá-la.

Devo registrar, ainda que rapidamente, o quanto Oslo é ao mesmo tempo tranquiila e cosmopolita: são elogiáveis a limpeza, o transporte público - com degraus baixos para facilitar o acesso a carrinhos de bebê e cadeiras de roda -, a justiça social; são ricos e variados os museus e espetáculos; é muito cordial a acolhida dos colegas do Instituto de Estudos Clássicos e Românicos, na estação Blinden do metrô, onde o professor visitante encontra sua mesa abastecida com diversos tipos de papel, caneta e envelope, numa sala com dois computadores, tendo ainda acesso à sala do fax e à do xerox.

Universidade de São Paulo 
Depoimento.

A Universidade de Oslo tem cursos de Português há mais de duas décadas. Em princípio, os estudantes de qualquer curso poderiam optar por Português, pois o aluno tem a possibilidade de montar seu próprio curriculum. Na época em que lá estive, no entanto, o interesse parecia concentrado no próprio departamento. O pequeno grupo que acompanhei declarou que pretendia se inscrever, posteriormente, em outra língua românica.

Os alunos de "minha" turma falavam e entendiam Português bastante bem, após dois anos de estudo, em média. No início, estranharam um pouco meu modo "brasileiro" de falar, porque estão mais acostumados à prosódia de Portugal. Depois se habituaram e o curso previsto para durar 16 horas/aula acabou sendo estendido para 18 horas/ aula. Houve ainda colóquios individuais ou em duplas, como apoio para a preparação do exame final, marcado para o final do mês de maio.

O programa centrou-se na linguagem literária de alguns autores modernistas: Manuel Bandeira, Carlos Drummond de Andrade, Graciliano Ramos e Clarice Lispector. Não conhecendo a biblioteca de lá - que, depois, pessoalmente, descobri ser ótima -, enviei, três meses antes, cópias dos textos que pretendia analisar, bem como de alguns ensaios teóricos que embasariam o curso, a fim de serem lidos com antecedência.

Logo no primeiro contato, percebi que os alunos tinham esses textos e que os haviam lido. No entanto, restava muito a esclarecer e aprofundar. Foi o que procurei fazer. Se uma palavra pudesse resumir meu trabalho, ela seria "leitura". As dificuldades com a língua propriamente dita eram mínimas, mas e o contexto? As especificidades do português do Brasil? Os traços culturais do país, direta ou indiretamente presentes nos poemas e narrativas? Foi preciso tratar de vários aspectos, essenciais na obra dos "clássicos" analisados, sem os quais elas não poderiam ser bem compreendidas. Cito dois exemplos, um deles relacionado à poesia e outro, à ficção.

1) As marcas da oralidade e a variante coloquial da linguagem, frequientes em nossa poesia modernista: 
No poema Irene no céu, de 0 ritmo dissoluto, de Manuel Bandeira, São Pedro convida: Entra, Irene, você não precisa pedir licença. (BANDEIRA, M. 1966, p.125). A mescla de "tu" e "você" situa a Irene do poema e do título num universo afetivo que a torna próxima do leitor. O tom não é solene, mas de conversa informal, o que é lingüisticamente marcado pela opção sintático-morfológica do poeta.

Em Belo belo, o poema $O$ bicho traz uma triste descrição: $O$ bicho não era um cão,/ Não era um gato,/ Não era um rato.// 0 bicho, meu Deus, era um homem. (BANDEIRA, M., O.C., p. 196) O tom de oralidade e o coloquialismo do apelo situam a cena como evento comum na vida dos que observam a nossa realidade. É importante salientar esse traço, tão distante da realidade norueguesa, onde as diferenças entre as classes sociais são muito pequenas.

No livro Alguma poesia, Drummond publicou um poema antológico, caracterizado pela reiteração de um verso, em que o verbo "haver" é coloquialmente substituído por "ter". Transcrevo a primeira estrofe:

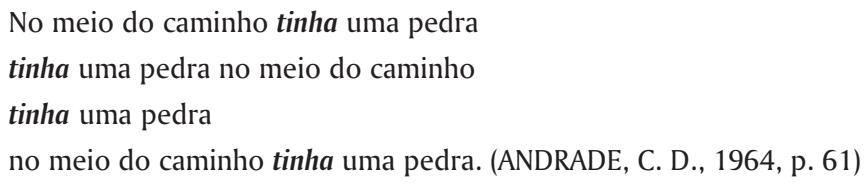

Por que "ter" por "haver"? A pedra metaforiza um obstáculo, do mesmo modo que a construção sintática do texto, cujo verso 3 permite três leituras (acoplado ao anterior, ao posterior ou independentemente). De que tipo de obstáculo se trata? A opção lexical pela variante coloquial aponta um obstáculo comum que qualquer cidadão enfrenta, inevitavelmente, no seu quotidiano. E que, como o verso 3 sugere, é contornado por um lado, pelo outro ou, colocado no meio do caminho, pode impedir a passagem (CANDIDO, A., 1970).

No mesmo livro, o Poema de sete faces conclui em tom de conversa, com estes versos: Eu não devia te dizer/ mas essa lua/ mas esse 
Depoimento.

conhaque/ botam a gente comovido como o diabo. (ANDRADE, C. D., O.C., p.53) $\mathrm{O}$ tom coloquial retorna, enfatizando as pequenas alegrias da vida, tão presentes na produção literária do Modernismo.

2) O contraste entre os cenários dos dois ficcionistas estudados parece ser determinante do estilo de cada obra. Em Vidas secas, a dureza da paisagem e do sistema condenam a família de tantos Fabianos à exclusão social, tornando-os incapazes de se comunicar verbalmente. No conto Cem anos de perdão, de Clarice Lispector, o universo urbano é ordenado, tem casas, jardins, pomares e nele as personagens infantis circulam sem medo. Ainda que, nas duas obras, as crianças tenham características comuns - o hábito de brincar e a capacidade de se encantar com alguma coisa -, o mundo que as cerca é diametralmente oposto, resultando em marcas linguiísticas e estilísticas específicas. Citações dos dois autores ilustram o processo.

Em Graciliano, os dois pequenos observadores mantêm-se distanciados do que vêem, temerosos diante do mundo exterior que sequer sabem nomear. $\mathrm{O}$ narrador em terceira pessoa verbal revela $\mathrm{o}$ menino mais novo e o menino mais velho de Vidas secas, empregando o discurso indireto livre para desvendar-lhes os pensamentos, quando eles ficam deslumbrados com a Festa de natal na vila: Tinham percebido que havia muitas pessoas no mundo. Ocupavam-se em descobrir uma enorme quantidade de objetos. Comunicaram baixinho um ao outro as surpresas que os enchiam. Impossível imaginar tantas maravilhas juntas /.../ Provavelmente aquelas coisas tinham nomes. /.../ Como podiam os homens guardar tantas palavras? ... (RAMOS, G., 1986, p. 84)

Em Clarice Lispector, o foco narrativo em primeira pessoa apresenta a voz da narradora-personagem evocando um episódio de sua infância. $\mathrm{O}$ mundo exterior está próximo da criança e a menina se comporta com ousadia, vivendo uma experiência estética e sensorial: ... Até chegar à rosa, foi um século de coração batendo. // Eis-me afinal 
Filologia e Lingüística Portuguesa, n. 2, p. 273-279, 1998.

diante dela. Paro um instante, porque de perto ela ainda é mais linda. Finalmente, começo a the quebrar o talo, arranhando-me com os espinhos e chupando o sangue dos dedos. /.../ O que é que eu fazia com a rosa? Fazia isso: ela era minha /.../ Foi tão bom. // Foi tão bom que simplesmente passei a roubar rosas. /.../ Também roubava pitangas. / .../ Mas pitangas são frutas que se escondem; eu não via nenhuma. /.../ eu metia a mão por entre as grades, mergulhava-a dentro da sebe e começava a apalpar até meus dedos sentirem o úmido da frutinha. ... (LISPECTOR, C., 1984, p.18)

Como o diálogo com os universitários foi contínuo, ao longo de três semanas, o olhar interrogativo deles, várias vezes, levava-me a perceber uma dúvida. Eu estava sendo entendida? Sim e não. Sim, se a pergunta se referisse aos dois eixos da língua, o lexical / paradigmático e o sintático / sintagmático. Não, se se pensasse no texto como um todo e na formação discursiva daqueles jovens. Para a leitura competente dos textos propostos, foi preciso também abordar os aspectos textuais e os discursivos.

Diz a canção de Caetano Veloso: Minha pátria é minha língua. Concordo plenamente. O "pacote" Curso de Português do Brasil, é inevitavelmente acompanhado pelo "pacote" Valores culturais do Brasil. Por mais que se esteja teoricamente preparado para essa situação, é surpreendente vivê-la na prática.

Tenho acompanhado as publicações teóricas voltadas para o estudo do texto, há muitos anos: dos procedimentos da analyse de texte e do new-criticism dos anos 50, às correntes mais recentes da análise do discurso e da lingüística textual, passando pelas teorias formais e estruturalistas dos anos 60 e 70, em suas várias vertentes. Foram muitas as oportunidades que tive de refletir sobre a multiplicidade de aspectos do texto. Nenhuma delas me pareceu tão impactante quanto a experiência de trabalho na Universidade de Oslo.

De modo menos forte uma palestra é apenas um contato rápido e passageiro -, tive a mesma percepção, na Universidade de Aårhus - onde 
Depoimento.

falei sobre Linguagem e estilo na poesia de Bandeira e Drummond -, e na de Estocolmo - onde tive oportunidade de fazer duas conferências: a primeira, estabelecendo um paralelo entre nossas Canções do exílio, do Romantismo e do Modernismo; e a segunda, sobre a Linguagem e estilo da literatura modernista brasileira. Ao notar a forma como estava sendo compreendida, logo após o início da fala, reduzi o conteúdo do que apresentaria, para dedicar mais tempo à leitura, comentário e análise dos textos literários.

Os alunos estrangeiros conseguem aprender Língua Portuguesa? Se considerarmos todas as variantes dela, a resposta se torna complexa; e se pensarmos em todos os aspectos do texto - os gramaticais, os textuais e os discursivos -, a complexidade se amplia ainda mais. Para uma resposta plena, seria necessário um projeto pedagógico e político amplo, com intenso intercâmbio acadêmico e muita reflexão sobre os "pacotes" que, a médio prazo, os professores visitantes das universidades brasileiras levarão na sua bagagem.

E eles, como podem retribuir? Ainda em 1997, a USP estará recebendo três visitas escandinavas: em agosto, o Prof. Lars Fant; em novembro, os Professores Kåre Nielsen e o Jorgen Schmitt Jensen, respectivamente das Univesidades de Estocolmo, Oslo e Aårhus. A presença deles deve propiciar uma reflexão complementar à precedente, no sentido de se estabelecer de que modo esses visitantes podem contribuir para difundir conhecimento entre nossos pesquisadores e se tornar seus interlocutores permanentes.

Há muito a ser pensado, planejado, executado. Seria importante que a universidade brasileira não perdesse a oportunidade de desempenhar o papel que lhe cabe, nessa região da Europa.

São Paulo, julho de 1997

\section{BIBLIOGRAFIA}

ANDRADE, C. D. de (1964) Obra completa. Rio de Janeiro, Aguilar. 
Filologia e Lingüística Portuguesa, n. 2, p. 273-279, 1998.

BANDEIRA, M. (1986) Estrela da vida inteira. Rio de Janeiro, Liv. Ed. José Olympio.

CANDIDO, A. (1970) Inquietudes na poesia de Drummond. In Vários escritos. São Paulo, Livraria Duas Cidades.

LISPECTOR, C. (1984) Cem anos de perdão. In Para gostar de ler número 9. São Paulo, Ática. RAMOS, G. (1986) Vidas secas. Rio / São Paulo, Record. 